\title{
Taeniid cestodes in a wolf pack living in a highly anthropic hilly agro-ecosystem
}

\author{
Fabio Macchioni ${ }^{1, a}$, Francesca Coppola ${ }^{1, a}$, Federica Furzi ${ }^{2}$, Simona Gabrielli $^{2}$, Samuele Baldanti $^{1}$, \\ Chiara Benedetta Boni ${ }^{1}$, and Antonio Felicioli ${ }^{1, *}$ \\ ${ }^{1}$ Department of Veterinary Sciences, University of Pisa, Viale delle Piagge 2, 56124 Pisa, Italy \\ 2 Department of Public Health and Infectious Diseases, Sapienza University of Rome, Piazzale Aldo Moro 5, 00185 Rome, Italy
}

Received 24 September 2020, Accepted 24 January 2021, Published online 5 February 2021

\begin{abstract}
The Italian wolf population in human-modified landscapes has increased greatly in the last few decades. Anthropisation increases the risk of transmission of many zoonotic infections and in this context, control of taeniid cestode species needs to be addressed from a One Health perspective. Predator-prey interactions are at the root of taeniid cestode transmission, and the wolf plays a key role in the maintenance and transmission of taeniids. To date, all available data on the taeniids of wolves in Italy refer to populations living in a wild habitat. Between 2018 and 2019 , we investigated taeniids in a wolf pack living in a highly anthropic hilly agro-ecosystem. Thirty-eight faecal samples were collected and analysed, 4 of which were also genetically characterised for individual wolves and belonged to three different animals. Samples collected were analysed microscopically and by molecular analysis in order to identify the taeniid species. Taeniid eggs were detected in $34.2 \%$ (13/38) of samples. Within samples positive to taeniid eggs only Echinococcus granulosus s.s. and Taenia hydatigena were identified in $26.3 \%$ and $10.5 \%$ of the samples, respectively. On microscopic examination, Capillaria spp., Ancylostomatidae and Toxocara canis eggs, Crenosoma vulpis larvae, and coccidian oocysts were also found. The combination of low biodiversity of taeniid species with a high occurrence of E. granulosus s.s. recorded in this study could be the consequence of a deeper link occurring between wolves and livestock in human-modified landscapes than in wild settings.
\end{abstract}

Key words: Anthropic areas, Canis lupus, Echinococcus granulosus s.s., Taenia hydatigena, Helminths, Parasites.

Résumé - Cestodes Taeniidae dans une meute de loups vivant dans un agroécosystème vallonné hautement anthropique. La population de loups italiens dans les paysages modifiés par l'homme a considérablement augmenté au cours des dernières décennies. L'anthropisation augmente le risque de transmission de nombreuses infections zoonotiques et, dans ce contexte, le contrôle des espèces de cestodes Taeniidae doit être abordé dans une perspective One Health. Les interactions prédateurs-proies sont à la base de la transmission des Cestodes Taeniidae, et le loup joue un rôle clé dans le maintien et la transmission des Taeniidae. À ce jour, toutes les données disponibles sur les Taeniidae du loup en Italie se réfèrent aux populations vivant dans un habitat sauvage. Entre 2018 et 2019, les Taeniidae d'une meute de loups vivant dans un agro-écosystème vallonné hautement anthropique ont été étudiés. Trente-huit échantillons fécaux ont été collectés et analysés, dont quatre ont également été génétiquement caractérisés pour des loups individuels et appartenaient à trois animaux différents. Les échantillons prélevés ont été analysés au microscope et par analyse moléculaire afin d'identifier les espèces de Taeniidae. Des œufs de Taeniidae ont été détectés dans 34,2 \% (13/38) des échantillons. Dans les échantillons positifs aux œufs de Taeniidae, seul Echinococcus granulosus s.s. et Taenia hydatigena ont été identifiés dans 26,3\% et 10,5\% des échantillons, respectivement. Lors de l'examen microscopique, des œufs de Capillaria spp., d'Ancylostomatidae et de Toxocara canis, des larves de Crenosoma vulpis et des oocystes de coccidie ont également été trouvés. La combinaison d'une faible biodiversité d'espèces de Taeniidae avec une forte occurrence d'E. granulosus s.s. rapportées dans cette étude pourrait être la conséquence d'un lien plus profond entre le loup et le bétail dans les paysages humains que dans les paysages sauvages.

\footnotetext{
*Corresponding author: antonio. felicioli@unipi.it
}

${ }^{\text {a }}$ These authors contributed equally to this work.

This is an Open Access article distributed under the terms of the Creative Commons Attribution License (https://creativecommons.org/licenses/by/4.0), which permits unrestricted use, distribution, and reproduction in any medium, provided the original work is properly cited. 


\section{Introduction}

The family Taeniidae includes four genera: Taenia Linnaeus, 1758, Echinococcus Rudolphi, 1801, Hydatigera Lamarck, 1816), and Versteria Nakao, Lavikainen, Iwaki, Haukisalmi, Konyaev, Oku, Okamoto \& Ito, 2013, which parasitise both mammals and humans [33, 47, 59]. Within the genera Taenia and Echinococcus, Taenia solium, Taenia saginata, Echinococcus granulosus s.l. and Echinococcus multilocularis are important pathogens causing food-borne zoonotic infections worldwide [15]. Tapeworm transmission is based on indirect domestic, semi-domestic and wildlife cycles involving various mammalian hosts including: (i) wild or domestic herbivores (prey), or (ii) wild or domestic canids or felids (predators) [33]. Occasionally, certain other zoonotic tapeworm species can also infect humans [33].

Predator-prey interactions are at the root of taeniid transmission, in which predators are the definitive hosts, while the prey is the intermediate host. This is referred to as a multi-host trophically-transmitted parasite system [3].

Among definitive hosts, the wolf (Canis lupus) plays a key role in the maintenance and transmission of several Taeniidae and could serve as a model species to better understand prey-predator and host-parasite dynamics [20]. Due to its top position in the wild trophic chain, the wolf hosts a wide gastrointestinal parasite community, which changes in relation to its diet [20].

As an opportunistic predator, the wolf selects its preys according to their local abundance, accessibility and vulnerability [39-41]. In Italy, the wolf's diet is mainly based on wild ungulates such as wild boar (Sus scrofa), roe deer (Capreolus capreolus), red deer (Cervus elaphus) and fallow deer (Dama dama), but it also preys upon livestock, especially goats (Capra hircus), sheep (Ovis aries) and calves (Bos taurus) [16, 32, 39, 42].

The Italian wolf population (C. lupus italicus, Altobello 1921), was in strong decline until the 1970s [60]; however, in the last few decades it has undergone natural re-expansion throughout the Alps and Apennines and in human-modified environments [14, 21].

The wolf's legal protection in Italy, which was established in 1976, together with changes in the ecology of mountain areas (e.g. decrease in human density and an increase in wild ungulates) as well as the natural reforestation of these areas, have promoted the wolf's re-colonisation of its historical distribution range [6, 8]. At the same time, the establishment of human activities in natural habitats has led to an increase in wolfhuman conflicts due to predation on livestock [41] and wolf/ domestic animal/human contact, with a high risk of pathogen transmission [29, 56]. Increased anthropisation may be a risk for the transmission of many zoonotic infections; furthermore some taeniid species are good examples to discuss the One Health perspective [29].

The Taeniidae of the Italian wolf population are still scarcely known and all the available data have been obtained from investigations performed in natural and semi-natural landscapes in the Apennines and Southern Alps [11, 18, 22$24,37,44,49]$. In these areas, $T$. hydatigena was the most frequently detected taeniid species in wolves, while $T$. multiceps,
T. krabbei, T. ovis, E. multilocularis and E. granulosus s.s. were also found in low frequency [22, 23, 37, 49].

Within the E. granulosus s.l. species cluster, E. granulosus s.s. and E. canadensis are mainly detected in wolves [23, 49, 57]. Echinococcus granulosus s.s., the major cause of cystic echinococcosis (CE) in humans in the world [1], is highly endemic in the Mediterranean basin, particularly in rural livestock-raising areas [10]. In these areas, the prevalence of E. granulosus s.l. in wolves is closely linked to the semidomestic cycle as a consequence of the high prevalence of cystic echinococcosis in sheep [24, 49].

Since no data are available on the Taeniidae population in wolves living in newly colonised, highly anthropic areas, the aim of this study was to investigate the Taeniidae in a wolf pack living in a highly anthropic hilly agroecosystem using noninvasive sampling. We predicted that in such areas, Taeniidae species from domestic intermediate hosts would be the most frequently recorded species associated with low taeniid biodiversity as a consequence of a deeper link occurring between wolves and livestock in human-modified landscapes than in wild environments.

\section{Materials and methods}

\section{Study area}

The study was carried out in a sub-urban, hilly area in Crespina-Lorenzana and Lari-Casciana Terme (43.551370 ${ }^{\circ}$ $10.551708^{\circ}$ ) in the Province of Pisa (central Italy). The study area of 900 ha is a highly anthropic, sub-urban, hilly, fragmented, woody agro-ecosystem where a wide variety of wildlife mammals live, such as crested porcupines (Hystrix cristata), wild boar (Sus scrofa), roe deer (Capreolus capreolus), pine martens (Martes martes), stone martens (Martes foina), European polecats (Mustela putorius), badgers (Meles meles), hares (Lepus europaeus), eastern cottontails (Sylvilagus floridanus), wild rabbits (Oryctolagus cuniculus), red foxes (Vulpes vulpes), and a large variety of small mammals. In the study area, small, woody areas are interspersed with human settlements, which lead to intensive interactions between the wildlife and productive and recreational activities of humans (i.e. sheep farming, forest cutting, trekking, cycling, horse riding, bird watching, and hunting). The study area includes 18 villages, with an average human density of 134.08 people/ $\mathrm{km}^{2}$. Extensive or semi-extensive sheep and cattle farming are the main husbandry economic activities in this area, mainly consisting of small farms (120-200 animals).

\section{Sample collection and parasitological analysis}

The parasitological investigations were carried out on wolf faecal samples collected between October 2018 and December 2019 within a larger non-invasive genetic monitoring project on a wolf pack (6-10 individuals), living in the study area. Whenever possible, faecal samples collected for genetic individual identification were also used for parasitological analysis. The faecal samples were collected along four transects (3 SD $1.2 \mathrm{~km}$ ), for a total length of $12 \mathrm{~km}$. Transects were randomly chosen within existing footpaths in the zones continuously 


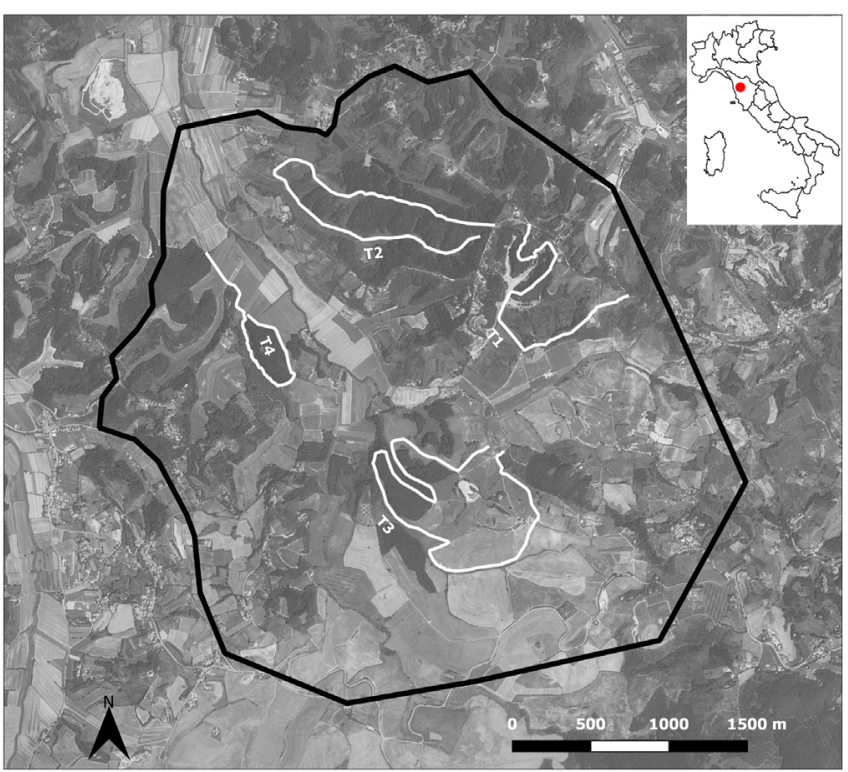

Figure 1. The sub-urban, hilly study area in Crespina-Lorenzana and Lari-Casciana Terme (black line border). The white lines indicate the four transects (T1-T4) where wolf faecal samples were collected. The location and country map are shown in the inset. The study area image was created using QGis 2.18 software.

monitored by camera-traps where transits and signs of presence (i.e. faeces, tracks, footprints, predations) of wolves were regularly recorded (Fig. 1).

Each transect was covered twice a week and all faeces were sampled, geolocated using GPS trackers and mapped in QGis 2.18 software. Since stray dogs were detected by camera-traps in the sampling area, size, shape, smell, composition (i.e. hair and parts of bones) and location of faeces were used to discriminate wolf and pet/hunting dog faeces [7-28]. The faecal samples collected were deep-frozen at $-80{ }^{\circ} \mathrm{C}$ for at least seven days for biosecurity reasons (inactivation of Taeniidae eggs, including E. granulosus s.l. and E. multilocularis) before performing the parasitological analysis [13].

An aliquot of $2 \mathrm{~g}$ of each faecal sample was placed in $15 \mathrm{~mL}$ tubes and used for Taeniidae egg isolation. In order to obtain a representative aliquot of each faecal sample collected, portions from the central part and the extremities were isolated. Taeniid eggs were isolated using flotation with zinc chloride $\left(\mathrm{ZnCl}_{2}\right)$ (specific gravity 1.350 solution) and the sieving method [38], and the morphological identification was carried out under a light microscope. During microscopic examination, co-infection by other parasites was also assessed.

\section{Molecular analysis}

Genomic DNA extraction and PCR amplification were performed on faecal samples that were found to be positive for taeniid eggs at the parasitological analysis. For DNA extraction, each faecal sample was suspended in PBS 1X, filtered and centrifuged at 13,000 rpm for $10 \mathrm{~min}$. The pellet obtained was then digested using $15 \mathrm{mg} / \mathrm{mL}$ proteinase $\mathrm{K}$ solution at $58{ }^{\circ} \mathrm{C}$ overnight and submitted to DNA extraction using a Fecal DNA kit (Bioline, United Kingdom), according to the
Table 1. Number of positive faecal samples for each identified parasite taxon.

\begin{tabular}{lc}
\hline Parasite & No. positive (\%) \\
\hline Capillaria spp. & $21 / 38(55.26 \%)$ \\
Ancylostomatidae eggs & $7 / 38(18.42 \%)$ \\
Crenosoma vulpis larvae & $5 / 38(13.15 \%)$ \\
Taeniidae eggs & $13 / 38(34.21 \%)$ \\
Toxocara canis & $2 / 38(5.26 \%)$ \\
Coccidian oocysts & $1 / 38(2.63 \%)$ \\
\hline
\end{tabular}

manufacturer's protocol. Partial sequences from the coxl and nadl gene marker were amplified following the PCR protocols proposed by Bowles et al. [5], Hüttner et al. [31], and Massolo et al. [37], including in each run, negative $\left(\mathrm{ddH}_{2} \mathrm{O}\right)$ and positive controls (Echinococcus granulosus DNA previously confirmed, Hammad et al. [27]). The amplicons were then purified and sequenced using Sanger automated sequencing by Bio-Fab Research (Rome, Italy). The resulting chromatograms were analysed and edited using Chromas v. 2.33 (Technelysium Pty Ltd, Australia). Readable sequences of partial coxl and nad1 were aligned using MEGA7 [34] and compared to GenBank retrieved homologous sequences (https://www.ncbi. nlm.nih.gov/genbank/).

\section{Results}

Overall, 38 wolf faecal samples were collected, of which $10.5 \%$ (4/38) were genetically characterized as belonging to three Italian wolf individuals. Microscopic examination evidenced taeniid eggs in $34.2 \%$ (13/38) of wolf faeces. Taeniid eggs were found in all samples belonging to the three genetically identified wolves. Taeniid DNA was successfully amplified with at least one target (coxl or nadl) in 10 out of 13 faecal samples containing taeniid eggs. Sequence analyses identified Echinococcus granulosus s.s. in $26.3 \%$ (10/38) and Taenia hydatigena in $10.5 \%$ (4/38) of analysed samples. All four positive samples for Taenia hydatigena showed co-infection with Echinococcus granulosus s.s., confirmed by the same identity score for the nadl sequences from the two parasites. Moreover, under microscopic examination, Capillaria spp., Ancylostomatidae and Toxocara canis eggs, Crenosoma vulpis larvae, and coccidian oocysts were also detected (Table 1). Multiple parasite infections were found in 14/38 (36.84\%) samples, while co-infestation of taeniid eggs with other parasites was detected in $8 / 38(21.05 \%)$ positive samples (Table 2 ).

\section{Discussion}

In this study, the taeniid species occurring in a wolf pack living in a highly anthropic, hilly, agro-ecosystem were investigated for the first time. Taeniidae eggs were detected in $34.2 \%$ of analysed samples. This result is consistent with the frequency detection of Taeniidae eggs in faecal samples of wolves living in the northern Apennines and southern Alps in Liguria reported by Gori et al. [22] (33\%, $n=179)$, in Foreste Casentinesi National Park by Poglayen et al. [49] ( $n=42.1 \%$, $n=130$ ), and higher than those reported by Massolo et al. [37] $(11.66 \%, n=120)$ in the south-western Italian Alps. 
Table 2. Multiple parasite infections found in the wolf faecal samples analysed.

\begin{tabular}{lccccc}
\hline Samples & $\begin{array}{c}\text { Taeniidae } \\
\text { eggs }\end{array}$ & $\begin{array}{c}\text { Capillaria } \\
\text { spp. }\end{array}$ & $\begin{array}{c}\text { Ancylostomatidae } \\
\text { eggs }\end{array}$ & $\begin{array}{c}\text { Crenosoma } \\
\text { vulpis } \\
\text { larvae }\end{array}$ & $\begin{array}{c}\text { Toxocara } \\
\text { canis }\end{array}$ \\
\hline 1 & $\mathrm{X}$ & $\mathrm{X}$ & $\mathrm{X}$ & & \\
2 & $\mathrm{X}$ & $\mathrm{X}$ & & $\mathrm{X}$ \\
3 & $\mathrm{X}$ & $\mathrm{X}$ & & & \\
4 & $\mathrm{X}$ & $\mathrm{X}$ & & & $\mathrm{X}$ \\
5 & $\mathrm{X}$ & $\mathrm{X}$ & $\mathrm{X}$ & $\mathrm{X}$ & \\
6 & $\mathrm{X}$ & $\mathrm{X}$ & $\mathrm{X}$ & \\
7 & & $\mathrm{X}$ & & $\mathrm{X}$ \\
8 & $\mathrm{X}$ & $\mathrm{X}$ & & $\mathrm{X}$ & \\
9 & $\mathrm{X}$ & $\mathrm{X}$ & $\mathrm{X}$ & & \\
10 & & $\mathrm{X}$ & $\mathrm{X}$ & & \\
11 & $\mathrm{X}$ & $\mathrm{X}$ & & & \\
13 & & & & & \\
\hline
\end{tabular}

Molecular amplification and identification by sequencing of taeniid species was obtained from 10 out of 13 faecal samples microscopically positive for Taeniidae eggs, while in the remaining three samples, no amplifiable products were obtained. This latter result is likely due to the sampling method as also reported in other studies [26, 52]. Importantly, the collection of faeces from the environment, as performed in this survey, represents a significant limiting factor in the extraction of high-quality target DNA in sufficient quantities. A long interval between faeces deposition on the soil and their collection can degrade the nucleic acid and increase the level of contamination by environmental organisms [52]. Such factors strongly reduce the possibility of DNA extraction and successful PCR amplification.

Sequence analyses of DNA extracted from faecal samples positive to taeniid eggs on microscopic examination allowed us to identify E. granulosus s.s. and T. hydatigena. However, the presence of other taeniid tapeworms in the analysed faecal samples cannot be ruled out, because the molecular protocol followed in this study preferentially amplified the predominant taeniid species. Cloning of the PCR product or high-resolution melting analysis is required to discriminate different species in the same host [9].

In this study, E. granulosus s.s. and T. hydatigena were detected in $26.3 \%(10 / 38)$ and $10.5 \%(4 / 38)$ of analysed faecal samples, respectively. In the wolf populations living in a natural landscape, E. granulosus s.l. has been detected in wolf faecal samples with a frequency of $5.6 \%(n=179)$ in the Northern Apennines-Southern Alps in Liguria [22] and in the Apennine chain, with a prevalence of $17 \%$ ( $\mathrm{n}=89$ wolves) [23] and $15 \%$ ( $n=119$ wolves), respectively [24]. Conversely, E. granulosus s.s. was found in wolf faecal samples living in the Foreste Casentinesi National Park $(2.3 \%, n=120)$, with a prevalence of 5.5\% ( $n=54$ wolves) [49] and E. granulosus (ovine genotype G1) was detected in Majella National Park in Abruzzo region with a prevalence of $5 \%(n=20$ wolves) [11]. Taenia hydatigena in wolves has been reported in mountainous, wild areas in the Northern Apennines-Southern Alps in Liguria and in the Apennine chain, with a frequency of $19.6 \%$ $(n=179)$ and a prevalence of $47 \%(n=89)$ respectively, while in the Foreste Casentinesi National Park with a frequency of $23.8 \%(n=120)[22,23,49]$.

The detection of E. granulosus s.s. as the main taeniid species and the detection of $T$. hydatigena in only a few samples in this wolf pack, in this specific, highly anthropic area, are particularly interesting compared to the high taeniid biodiversity detected in wolf populations living in wild mountain areas of the Apennines [22, 23, 49], as well as in other European countries [4, 25, 43] (Table 3 ). Also in wild, mountainous areas of the Alps, higher taeniid biodiversity was recorded compared to that detected in this study [37]. In this case, it is important to point out that this difference could be due also to the different taeniid DNA extraction protocols used, from faecal samples in this study and from taeniid eggs by Massolo et al. [37]. In wild habitats, the wolf was identified as the definitive host of several Taeniidae species, among which $T$. hydatigena was the most frequently detected species followed by T. multiceps, T. ovis, T. krabbei, T. pisiformis, T. crassiceps, T. polyacantha, E. ortleppi, E. multilocularis and E. granulosus, suggesting a more diversified multi-host parasite system [22, 23, 37, 49]. All these Taeniidae species are recorded throughout Europe in several intermediate hosts, such as large ungulates, lagomorphs and small mammals [36, 45, 46, 55].

Echinococcus granulosus s.l. is widespread in the Mediterranean basin, especially in Spain and Italy (southern Italy and Sardinia), with over 1000 human cystic echinococcosis (CE) cases per year in both countries $[10,50]$. The life cycle of E. granulosus s.s is mostly domestic or semi-domestic, involving $\operatorname{dogs}$ as the most important definitive host, and wolves and domestic ungulates as intermediate hosts [51]. Sheep and more rarely goats are the most important domestic intermediate hosts for E. granulosus s.s, which may also infect other herbivorous hosts (e.g. cattle, camels, donkeys and macropods) [51]. Taenia hydatigena is a very generalist taeniid species, which parasitises as the larval stage (Cysticercus tenuicollis) a wide range of intermediate hosts, both domestic animals (i.e. sheep) and wild ungulates (i.e. mouflon, red deer, roe deer, fallow deer and wild boar) $[19,36,45,48,53,54]$. 
Table 3. Taeniid biodiversity detected in different wolf populations living in the Apennines and Southern Alps in Italy and in other European countries. For each Taeniidae, the frequency or prevalence detected are reported if provided in the respective literature sources.

\begin{tabular}{|c|c|c|}
\hline Taeniid species & Area & Reference \\
\hline Taenia hydatigena $(47 \%) *$ & Apennine chain & Guberti et al. [23] \\
\hline \multicolumn{3}{|l|}{ Taenia multiceps $(9 \%)^{*}$} \\
\hline \multicolumn{3}{|l|}{ Taenia pisiformis $(7 \%)^{*}$} \\
\hline \multicolumn{3}{|l|}{ Taenia ovis $(3 \%)^{*}$} \\
\hline \multicolumn{3}{|l|}{ Echinococcus granulosus s.l. $(17 \%)^{*}$} \\
\hline Taenia hydatigena $(40.7 \%)^{* *}$ & Northern Apennines-Southern Alps (Liguria) & Gori et al. [22] \\
\hline \multicolumn{3}{|l|}{ Taenia ovis $(2.2 \%)^{* *}$} \\
\hline \multicolumn{3}{|l|}{ Taenia krabbei $(4.5 \%)^{* *}$} \\
\hline \multicolumn{3}{|l|}{ Taenia crassiceps $(0.6 \%)^{* *}$} \\
\hline \multicolumn{3}{|l|}{ Hydatigera taeniaeformis $(0.6 \%)^{* *}$} \\
\hline \multicolumn{3}{|l|}{ Echinococcus granulosus s.l. $(5.6 \%)^{* *}$} \\
\hline Taenia ovis & Modena Apennines & Fiocchi et al. [18] \\
\hline \multicolumn{3}{|l|}{ Taenia hydatigena } \\
\hline Taenia hydatigena $(40.7 \%)^{*}$ & Foreste Casentinesi National Park, Northern Italian Apennines & Poglayen et al. [49] \\
\hline \multicolumn{3}{|l|}{ Taenia krabbei $(22.2 \%)^{*}$} \\
\hline \multicolumn{3}{|l|}{ Taenia polyachantha $(1.8 \%)^{*}$} \\
\hline \multicolumn{3}{|l|}{ Echinococcus granulosus s.s. $(5.5 \%)^{*}$} \\
\hline Taenia hydatigena & Ligurian Alps Regional Park, Italian Maritime Alps & Massolo et al. [37] \\
\hline \multicolumn{3}{|l|}{ Taenia krabbei } \\
\hline \multicolumn{3}{|l|}{ Taenia ovis } \\
\hline \multicolumn{3}{|l|}{ Taenia multiceps } \\
\hline \multicolumn{3}{|l|}{ Echinococcus ortleppi } \\
\hline \multicolumn{3}{|l|}{ Echinococcus multilocularis } \\
\hline Taenia hydatigena $(12 \%)^{*}$ & Estonia & Moks et al. [43] \\
\hline \multicolumn{3}{|l|}{ Taenia multiceps $(27 \%)^{*}$} \\
\hline \multicolumn{3}{|l|}{ Taenia ovis $(15 \%)^{*}$} \\
\hline \multicolumn{3}{|l|}{ Taenia pisiformis $(8 \%)^{*}$} \\
\hline \multicolumn{3}{|l|}{ Echinococcus granulosus s.l. (4\%)* } \\
\hline Taenia hydatigena $(13.3 \%)^{* *}$ & Germany & Bindke et al. [4] \\
\hline \multicolumn{3}{|l|}{ Taenia krabbei $(13.3 \%)^{* *}$} \\
\hline Taenia hydatigena $(11.8 \%)^{* *}$ & Portugal & Guerra et al. [25] \\
\hline \multicolumn{3}{|l|}{ Taenia serialis $(5.9 \%)^{* *}$} \\
\hline \multicolumn{3}{|l|}{ Taenia pisiformis $(2.9 \%)^{* *}$} \\
\hline \multicolumn{3}{|l|}{ Taenia polyachantha $(1.5 \%) * *$} \\
\hline Echinococcus intermedius (G7) $(1.5 \%)^{* *}$ & & \\
\hline
\end{tabular}

${ }^{*}$ Percentage refers to a prevalence.

*** Percentage refers to a frequency.

The highly anthropic, sub-urban, hilly area in which this study was performed is characterised by the presence of extensive sheep farming, the availability of wild prey, and close contact between domestic animals, humans and wildlife. These features make this area completely different from the Alps and Apennine mountain habitats. In anthropic rural areas, livestock (i.e. sheep and goats), which are easily accessible and highly vulnerable, and wild ungulates, which recently increased their diffusion in urbanised areas are an important source of food for wolves [40, 41]. In the study area, wolf attacks on sheep and goats were regularly recorded during the investigation period (unpublished data). No data are available concerning the frequency of livestock and wild prey in the wolf diet in anthropic areas, and there is a lack of information on the frequency and prevalence of echinococcosis and cysticercosis in livestock and wildlife in anthropic agro-ecosystems.

Therefore, the high detection of E. granulosus s.s. found in this investigation should be ascribed to the highly anthropised environment with a high livestock density. No wild cycle of
E. granulosus s.l. has been described in Italy, even though, the wild boar was recently found to be a wild intermediate host of E. granulosus s.l. and Taenia hydatigena [12, 35, 48, 58]. Moreover, differences occurring in taeniid biodiversity in wolves living in anthropic areas could be the result of a combined effect of a low occurrence of taeniids in wild prey and a lower frequency of wild prey in the diet of wolves in anthropic areas than in those living in natural landscapes.

All four positive samples for Taenia hydatigena in this study showed co-infection with E. granulosus s.s. Taeniid co-infection in wild wolf populations was previously reported with T. hydatigena and E. granulosus s.l. by Gori et al. [22] and with E. multilocularis and T. hydatigena, T. krabbei, T. ovis, or E. ortleppi by Massolo et al. [37]. Moreover, co-infection with T. hydatigena and E. granulosus s.l. was also recorded in wild boar hunted in two National parks in Central Italy [48].

In this study, microscopic examination also demonstrated the occurrence of Capillaria spp., Ancylostomatidae eggs, 
Crenosoma vulpis larvae, Toxocara canis and coccidian oocysts, as previously detected in wolves both from Italy and other countries in Europe [2, 17, 18, 23, 30, 44].

In conclusion, the results obtained in this investigation support the prediction that: (i) E. granulosus s.s. is the most frequently recorded taeniid species in wolves living in highly anthropised, hilly agro-ecosystems as a consequence of a deeper link occurring between wolves and livestock, (ii) taeniid biodiversity is lower than in wolves living in wild habitats, even though this result needs to be reinforced by further investigations using DNA extraction directly from taeniid eggs, rather than from faecal samples. Moreover, the results obtained indicate that co-infection with several taeniid species occurred in wolves. Further studies are needed in order to assess the taeniid species frequency occurring in wolves from other anthropised areas. In addition, investigations on wolf diet composition in anthropic areas compared to that of wild individuals would be useful.

\section{Funding and source}

This study was funded by Fondi di Ateneo of the University of Pisa, Italy.

\section{Conflict of interest}

The authors declare that they have no conflict of interest.

\section{Author contributions}

Conceived the study: AF, FM, FC; Designed the experiment: AF, FM, FC; Performed the field activities and sampling: AF, FC, SB, CBB; Performed the laboratory work: FM, FF, SG; Analysed and interpreted the data: AF, FM, FC, FF, SG, $\mathrm{SB}, \mathrm{CBB}$; Wrote the original draft of the manuscript: AF, FM, FC, FF, CBB; Reviewed and edited the final version of the manuscript: AF, FM, FC, SG, FF, SB, CBB; Supervision: AF.

\section{References}

1. Alvarez Rojas CA, Romig T, Lightowlers MW. 2014. Echinococcus granulosus sensu lato genotypes infecting humans-review of current knowledge. International Journal of Parasitology, 44, 9-18.

2. Ambrogi C, Ragagli C, Decaro N, Ferroglio E, Mencucci M, Apollonio M, Mannelli A. 2019. Health survey on the wolf population in Tuscany, Italy. Hystrix, 30(1), 19-23.

3. Baudrot V, Perasso A, Fritsch C, Raoul F. 2016. Competence of hosts and complex foraging behavior are two cornerstones in the dynamics of trophically transmitted parasites. Journal of Theoretical Biology, 397, 158-168.

4. Bindke JD, Springer A, Janecek-Erfurth E, Boer M, Strube C. 2019. Helminth infections of wild European wolves (Canis lupus Linnaeus, 1758) in Lower Saxony, Germany, and comparison to captive wolves. Parasitology Research, 118, 701-706.

5. Bowles J, Blair D, McManus DP. 1992. Genetic variants within the genus Echinococcus identified by mitochondrial sequencing. Molecular and Biochemical Parasitology, 54, 165-174.
6. Breitenmoser U. 1998. Large predators in the Alps: the fall and rise of man's competitors. Biological Conservation, 83(3), 279-289.

7. Chame M. 2003. Terrestrial mammal feces: a morphometric summary and description. Memorias do Instituto Oswaldo Cruz, Rio de Janeiro, 98, 71-94.

8. Ciancio O, Corona P, Lamonaca A, Portoghesi L, Travagini D. 2006. Conversion of clearcut beech coppices into high forests with continuous cover: a case study in central Italy. Forest Ecology and Management, 224, 235-240.

9. Dehghani M, Mohammadi MA, Rostami S, Shamsaddini S, Mirbadie SR, Harandi MF. 2016. High-resolution melting analysis (HRM) for differentiation of four major Taeniidae species in dogs Taenia hydatigena, Taenia multiceps, Taenia ovis, and Echinococcus granulosus sensu stricto. Parasitological Research, 115(7), 2715-2720.

10. Deplazes P, Rinaldi L, Alvarez Rojas CA, Torgerson PR, Harandi MF, Romig T, Antolova D, Schurer JM, Lahmar S, Cringoli G, Magambo J, Thompson RCA, Jenkins EJ. 2017. Global distribution of alveolar and cystic echinococcosis, in Echinococcus and Echinococcosis Part A, Thompson RCA, Deplazes P, Lymbery AJ, Editors. Advance in Parasitology. p. 315-493.

11. Di Francesco CE, Smoglica C, Paoletti B, Angelucci S, Innocenti M, Antonucci A, Di Domenico G, Marsilio F. 2019. Detection of selected pathogens in Apennine wolf (Canis lupus italicus) by a non-invasive GPS-based telemetry sampling of two packs from Majella National Park, Italy. European Journal of Wildlife Research, 65, 84.

12. Di Paolo A, Piseddu T, Sebastianelli M, Manuali E, Corneli S, Paniccia M, Papa P, Viali S, Mazzone P. 2017. Detection of Echinococcus granulosus G3 in Wild Boar (Sus scrofa) in Central Italy using PCR and Sequencing. Journal of Wildlife Diseases, 53(2), 399-401.

13. Eckert J, Gemmell MA, Meslin FX, Pawlowski ZS. 2001. WHO/OIE manual on Echinococcosis in humans and animals: a public health problem of global concern. France: WHOIOIE Paris.

14. Fabbri E, Miquel C, Lucchini V, Santini A, Caniglia R, Duchamp C, Weber JM, Lequette B, Marucco F, Boitani L, Fumagalli L, Taberlet P, Randi E. 2007. From the Apennines to the Alps: colonization genetics of the naturally expanding Italian wolf (Canis lupus) population. Molecular Ecology, 16, 1661-1671.

15. FAO/WHO. 2014. Multicriteria-based ranking for risk management of food-borne parasites. Microbiological Risk Assessment Series 23, Rome.

16. Ferretti F, Lovari S, Mancino V, Burrini L, Rossa M. 2019. Food habits of wolves and selection of wild ungulates in a preyrich Mediterranean coastal area. Mammalian Biology, 99, 119127.

17. Figueiredo A, Oliveira L, de Carvalho LM, Fonseca C, Torres RT. 2016. Parasite species of the endangered Iberian wolf (Canis lupus signatus) and a sympatric widespread carnivore. International Journal of Parasitology: Parasites and Wildlife, 5 (2), 164-167.

18. Fiocchi A, Gustinelli A, Gelmini L, Rugna G, Renzi M, Fontana MC, Poglayen G. 2016. Helminth parasites of the red fox Vulpes vulpes (L.,1758) and the wolf Canis lupus italicus Altobello, 1921 in Emilia-Romagna, Italy. Italian Journal of Zoology, 83(4), 503-513.

19. Formenti N, Chiari M, Trogu T, Gaffuri A, Garbarino C, Boniotti MB, Corradini C, Lanfranchi P, Ferrari N. 2018. Molecular identification of cryptic cysticercosis: Taenia ovis krabbei in wild intermediate and domestic definitive hosts. Journal of Helminthology, 92, 203-209. 
20. Friesen OC, Roth JD. 2016. Alternative prey use affects helminth parasite infections in grey wolves. Journal of Animal Ecology, 85, 1265-1274.

21. Galaverni M, Caniglia R, Fabbri E, Milanesi P, Randi E. 2016. One, no one, or one hundred thousand: how many wolves are there currently in Italy? Mammal Research, 61(1), 13-24.

22. Gori F, Armua-Fernandez MT, Milanesi P, Serafini M, Magi M, Deplazes P, Macchioni F. 2015. The occurrence of taeniids of wolves in Liguria (northern Italy). International Journal of Parasitology: Parasites and Wildlife, 4, 252-255.

23. Guberti V, Stancampiano L, Francisci F. 1995. Intestinal helminth parasite community in wolves (Canis lupus) in Italy. Parassitologia, 55, 59-65.

24. Guberti V, Bolognini M, Lanfranchi P, Battelli G. 2004. Echinococcus granulosus in the wolf in Italy. Parassitologia, 46(4), 425-427.

25. Guerra D, Armua-Fernandez MT, Silva M, Bravo I, Santos N, Deplazes P, Madeira de Carvalho LM. 2013. Taeniid species of the Iberian wolf (Canis lupus signatus) in Portugal with special focus on Echinococcus spp. International Journal of Parasitology: Parasites and Wildlife, 2, 50-53.

26. Hàjkovà $\mathrm{P}$, Zemanovà $\mathrm{B}$, Bryja $\mathrm{J}$, Hàjek $\mathrm{B}$, Roche $\mathrm{K}$, Tkadlec $\mathrm{E}$, Zima J. 2006. Factors affecting success of PCR amplification of microsatellite loci from otter faeces. Molecular Ecology Notes, 6, 559-562.

27. Hammad SJ, Cavallero S, Milardi GL, Gabrielli S, D Amelio S, Al-Nasiri FS. 2018. Molecular genotyping of Echinococcus granulosus in the North of Iraq. Veterinary Parasitology, 249, $82-87$.

28. Harrington FH, Asa CS. 2003. Wolf communication, in Wolves: Behaviour, Ecology and Conservation, Mech LD, Boitani L, Editors. The University of Chicago Press: Chicago. p. 66-103.

29. Hassell JM, Begon M, Ward MJ, Fevre EM. 2017. Urbanization and disease emergence: dynamics at the wildlife-livestockhuman interface. Trends in Ecology \& Evolution, 32(1), 55-67.

30. Hermosilla C, Kleinertz S, Silva LMR, Hirzmann J, Huber D, Kusak J, Taubert A. 2017. Protozoan and helminth parasite fauna of free-living Croatian wild wolves (Canis lupus) analyzed by scat collection. Veterinary Parasitology, 233, 14-19.

31. Hüttner M, Nakao M, Wassermann T, Siefert L, Boomker JD, Dinkel A, Sako Y, Mackenstedt U, Romig T, Ito A. 2008. Genetic characterization and phylogenetic position of Echinococcus felidis (Cestoda: Taeniidae) from the African lion. International Journal of Parasitology, 38, 861-868.

32. Imbert C, Caniglia R, Fabbri E, Milanesi P, Randi E, Serafini M, Torretta E, Meriggi A. 2016. Why do wolves eat livestock? Factors influencing wolf diet in northern Italy. Biological Conservation, 195, 156-168.

33. Knapp J, Nakao M, Yanagida T, Okamoto M, Saarma U, Lavikainen A, Ito A. 2011. Phylogenetic relationships within Echinococcus and Taenia tapeworms (Cestoda: Taeniidae): an inference from nuclear protein-coding genes. Molecular Phylogenetics and Evolution, 61, 628-638.

34. Kumar S, Stecher G, Tamura K. 2016. MEGA7: molecular evolutionary genetics analysis version 7.0 for bigger datasets. Molecular Biology and Evolution, 33, 1870-1874.

35. Laurimäe T, Kinkar L, Varcasia A, Dessì G, Sgroi G, D’Alessio N, Veneziano V, Saarma U. 2019. First detection of zoonotic tapeworm Echinococcus granulosus sensu lato genotype G7 in continental Italy. Parasitology Research, 118(7), 2193-2201.

36. Letková V, Lazar P, Soroka J, Goldová M, Curlík J. 2008. Epizootiology of game cervid cysticercosis. Natura Croatica, 17(4), 311-318.
37. Massolo A, Valli D, Wassermann M, Cavallero S, D'Amelio S, Meriggi A, Torretta E, Serafini M, Casulli A, Zambon L, Boni CB, Ori M, Romig T, Macchioni F. 2018. Unexpected Echinococcus multilocularis infections in shepherd dogs and wolves in southwestern Italian Alps: a new endemic area? International Journal of Parasitology: Parasites Wildlife, 7, 309-316.

38. Mathis A, Deplazes P, Eckert J. 1996. An improved test system for PCR-based specific detection of Echinococcus multilocularis eggs. Journal of Helminthology, 70, 219-222.

39. Mattioli L, Capitani C, Fazzola A, Scandura M, Apollonio M. 2011. Prey selection and dietary response by wolves in a highdensity multi-species ungulate community. European Journal of Wildlife Research, 57, 909-922.

40. Meriggi A, Brangi A, Schenone L, Signorelli D, Milanesi P. 2011. Changes of wolf (Canis lupus) diet in Italy in relation to the increase of wild ungulate abundance. Ethology Ecology \& Evolution, 23, 195-210.

41. Meriggi A, Degradi V, Dondina O, Perversi M, Milanesi P, Lombardini M, Raviglione S, Repossi A. 2015. Short-term responses of wolf feeding habits to changes of wild and domestic ungulate abundance in Northern Italy. Ethology Ecology \& Evolution, 27(4), 389-411.

42. Milanesi P, Meriggi A, Merli E. 2012. Selection of wild ungulates by wolves Canis lupus (L. 1758) in an area of the Northern Apennines (North Italy). Ethology Ecology \& Evolution, 24(1), 81-96.

43. Moks E, Jogisalu I, Saarma U, Talvik H, Jarvis T, Valdmann H. 2006. Helminthologic survey of the wolf (Canis lupus) in Estonia, with an emphasis on Echinococcus granulosus. Journal of Wildlife Diseases, 42(2), 359-365.

44. Molnar B, Ciucci P, Mastrantonio G, Betschart B. 2019. Correlates of parasites and pseudoparasites in wolves (Canis lupus) across continents: a comparison among Yellowstone (USA), Abruzzo (IT) and Mercantour (FR) national parks. International Journal of Parasitology: Parasites Wildlife, 10, 196-206.

45. Murai É, Sugár L. 1979. Taeniid species in Hungary (Cestoda, Taeniidae). I. Cysticercosis, coenurosis and hydatidosis of wild ungulates. Parasitologia Hungarica, 12, 41-52.

46. Murai É. 1982. Taeniid species in Hungary (Cestoda: Taeniidae). II. Larval stages of taeniids parasitizing rodents and lagomorphs. Miscellanea Zoologica Hungarica, 1, 27-44.

47. Nakao M, Lavikainen A, Iwaki T, Haukisalmi V, Konyaev S, Oku Y, Okamoto M, Ito A. 2013. A Molecular phylogeny of the genus Taenia (Cestoda: Taeniidae): proposals for the resurrection of Hydatigera Lamarck, 1816 and the creation of a new genus Versteria. International Journal for Parasitology, 43, 427-437.

48. Paoletti B, Della Salda L, Di Cesare A, Iorio R, Vergara A, Fava C, Olivastri A, Dessi G, Scala A, Varcasia A. 2019. Epidemiological survey on cystic echinococcosis in wild boar from Central Italy. Parasitological Research, 118, 43-46.

49. Poglayen G, Gori F, Morandi B, Galuppi R, Fabbri E, Caniglia R, Milanesi P, Galaverni M, Randi E, Marchesi B, Deplazes P. 2017. Italian wolves (Canis lupus italicus Altobello, 1921) and molecular detection of taeniids in the Foreste Casentinesi National Park, Northern Italian Apennines. International Journal of Parasitology: Parasites and Wildlife, 6, 1-7.

50. Romig T, Dinkel A, Mackenstedt U. 2006. The present situation of echinococcosis in Europe. Parasitology International, 55 (Suppl), S187-S191.

51. Romig T, Deplazes P, Jenkins D, Giraudoux P, Massolo A, Craig PS, Wassermann M, Takahashi K, de la Rue M. 2017. 
Ecology and life cycle patterns of Echinococcus species. Advances in Parasitology, 95, 213-314.

52. Rutledge LY, Holloway JJ, Patterson BR, White BN. 2009. An improved field method to obtain DNA for individual identification from wolf scat. Journal of Wildlife Management, 73(8), 1430-1435.

53. Scala A, Pipia AP, Dore F, Sanna G, Tamponi C, Marrosu R, Bandino E, Carmona C, Boufana B, Varcasia A. 2015. Epidemiological updates and economic losses due to Taenia hydatigena in sheep from Sardinia, Italy. Parasitological Research, 114(8), 3137-3143.

54. Sgroi G, Varcasia A, Dessì G, D'Alessio N, Pacifico L, Buono F, Neola B, Fusco G, Santoro M, Toscano V, Fioretti A, Veneziano V. 2019. Massive Taenia hydatigena Cysticercosis in a Wild Boar (Sus scrofa) from Italy. Acta Parasitologica, 64(4), 938-941.

55. Stancampiano L, Ravagnan S, Capelli G, Militerno G. 2019. Cysticercosis by Taenia pisiformis in Brown Hare (Lepus europaeus) in Northern Italy: epidemiologic and pathologic features. International Journal of Parasitology: Parasites and Wildlife, 9, 139-143.

56. Thompson RCA. 2013. Parasite zoonoses and wildlife: one health, spillover and human activity. International Journal of Parasitology, 43, 1079-1088.

57. Thompson RCA. 2020. The molecular epidemiology of Echinococcus infections. Pathogens, 9(6), 453.

58. Varcasia A, Piseddu T, Pipia AP, Schianchi G, Marongiu A, Petruzzi V, Scala A, Garippa G. 2008. Epidemiological and biomolecular updates on cystic echinococcosis in pigs and wild boars of Sardinia (Italy). Lucrari Stiintifice Medicina Veterinara, $41,385-387$.

59. Vuitton DA, McManus DP, Rogan MT, Romig T, Gottstein B, Naidich A, Tuxun T, Wen H, da Silva AM. 2020. International consensus on terminology to be used in the field of echinococcoses. Parasite, 27, 41.

60. Zimen E, Boitani L. 1975. Number and distribution of wolves in Italy. Zeitschrift fur Säugetierkunde, 40, 102-112.

Cite this article as: Macchioni F, Coppola F, Furzi F, Gabrielli S, Baldanti S, Boni CB \& Felicioli A. 2021. Taeniid cestodes in a wolf pack living in a highly anthropic hilly agro-ecosystem. Parasite $\mathbf{2 8}, 10$.

\section{- PARASTE}

An international open-access, peer-reviewed, online journal publishing high quality papers on all aspects of human and animal parasitology

Reviews, articles and short notes may be submitted. Fields include, but are not limited to: general, medical and veterinary parasitology; morphology, including ultrastructure; parasite systematics, including entomology, acarology, helminthology and protistology, and molecular analyses; molecular biology and biochemistry; immunology of parasitic diseases; host-parasite relationships; ecology and life history of parasites; epidemiology; therapeutics; new diagnostic tools.

All papers in Parasite are published in English. Manuscripts should have a broad interest and must not have been published or submitted elsewhere. No limit is imposed on the length of manuscripts.

Parasite (open-access) continues Parasite (print and online editions, 1994-2012) and Annales de Parasitologie Humaine et Comparée (1923-1993) and is the official journal of the Société Française de Parasitologie. 